Cumhuriyet International Journal of Education-CIJE

e-ISSN: 2147-1606

Vol 6 (1), 2017, 123 - 139

\title{
An Investigation of Preschool Children's Knowledge about Child Sexual Abuse: A Qualitative View
}

\author{
Özlem Alkan ERSOY, Hurşide Kübra ÖZKAN
}

\section{Summary}

\section{INTRODUCTION}

Studies on "Child Sexual Abuse" are mainly based on the purpose of altering children's behaviors and providing them with necessary information. These studies teaching children how to protect themselves from sexual abuse, from whom and how to ask help when subjected to sexual abuse play a crucial role on preventing sexual abuse. Therefore, the current study aims to investigate 5-6 year-old preschool children's knowledge about sexual abuse.

\section{METHOD}

This study used a qualitative research model and one-group pretest-posttest weak experimental design. The study group included 24 preschool children who were 5-6 years of age. Data was collected through drawing and interview techniques both. A semi-structured interview form was created by the researchers in order to carry out interviews with the children. This form consisted of six questions that assessed the children's safety knowledge about sexual abuse. Each child was asked the questions, "Can you touch anybody's body?", "Can anybody touch your body?", "Do you think there is good touch and bad touch?", "What do you think these might be?", "What would you do if someone you didn't know wanted to touch you in a bad way?", "Whom would you tell if someone touched you in a bad way?", and "Why would you prefer to tell that person?" and, when necessary, additional relevant questions were asked. At first, pre-interviews were conducted to assess the children's knowledge about sexual abuse. The story book titled "My Body Belongs To Me" published by Pro Familia was used to enlighten the children on this topic. Three specialists studying on this subject were consulted about choosing the right book. Having been read the story, children were asked the question "What would you do if you were this child in the story?" and instructed to draw without any time limitation. Children who had finished the drawing were asked what they drew and the researcher took notes of their explanations behind the paper they drew on. Final interviews were done four days after this activity to investigate whether the group's knowledge level changed in terms of dependent variables.

Collected data was analyzed through a content analysis during the evaluation of pretest-posttest interviews conducted with the study group. During the drawing activity, which was carried out to ensure the reliability of posttest interview questions, children's drawings were analyzed by a content analysis method. Analyses performed and the specialists' decisions on the indicator types were coded separately and reliability of the study was calculated by using the formula, Reliability $=$ Agreement/Agreement+Disagreement $x$ 100. According to the agreement meeting held with three specialists, coder concordance between the researchers was calculated as $100 \%$ for the drawing technique, and $92 \%$ for the interviews. 


\section{RESULTS AND SUGGESTIONS}

The results of the study showed that the children had incomplete or inaccurate knowledge about the difference between good touch and bad touch, how to protect themselves from sexual abuse, and from whom and how to ask help when subjected to sexual abuse. However, the story activity provided valuable information on sexual abuse to the children and raised their awareness about how to take adequate precautions. Thus, teaching children about sexual abuse must be mandatory. In this regard, starting from preschool period, integrating the subjects concerning sexuality and sexual abuse into the curriculum becomes crucially important. 